\title{
Aplicação do método Pensar-Emparelhar-Compartilhar no Ensino de Física
}

\author{
Ferreira, M. I. A. ${ }^{*}$; Alvarenga, F. G. ${ }^{2}$ \\ 1 Programa de Pós-Graduação em Ensino na Educação Básica, Universidade Federal do Espírito Santo, \\ Campus São Mateus, ES, Brasil. \\ 2 Departamento de Ciências Naturais, Universidade Federal do Espírito Santo, Campus São Mateus, ES, Brasil. \\ * e-mail: mariaines12990@gmail.com
}

\begin{abstract}
Resumo
Em um ambiente ativo de ensino e aprendizado, a sala de aula se torna um lugar para troca de conhecimentos onde os alunos se desprendem do papel de simples receptores de informação para se tornarem também participantes ativos da aula e professores deixam de ser apenas transmissores de informação, tornando-se também facilitadores do aprendizado. A criação de tal ambiente visa tornar o aluno mais independente no processo de aprendizagem, ensinando-o a "aprender a aprender." Para isso, faz-se uso das chamadas metodologias ativas, as quais auxiliam na dialética e interação da turma. Para esse artigo, analisamos a aplicação de um método ativo chamado Pensar-Emparelhar-Compartilhar (Think-Pair-Share) em uma turma de Eletromagnetismo composta por alunos de engenharia. O tema abordado foi "indução eletromagnética", sendo divido em três aulas: a primeira sobre lei de Faraday e lei de Lenz; a segunda, força eletromotriz produzida pelo movimento e campo elétrico induzido; e a terceira, correntes de Foucault. As aulas foram ministradas na UFES, no campus de São Mateus. Durante as aulas, os alunos se mostraram receptivos ao método utilizado e, por meio de testes conceituais, constatamos que o aprendizado também foi beneficiado.
\end{abstract}

Palavras-chaves: ensino de física, aprendizado ativo, pensar-emparelhar-compartilhar.

\begin{abstract}
In active learning environments, the classroom becomes a place for knowledge exchange where students are less of just receivers of information but more of active participants of the class and teachers are not only providers of information but also facilitators of learning. Such environment aims on the improvement of student's independence in the learning process, helping them "learn how to learn." For such, so called active methodologies are devised to help dialectic and interaction in class. In this paper, we analyze the use of an active learning method called Think-Pair-Share in an Electromagnetism class for engineering students. The chosen topic was "electromagnetic induction", being covered in three classes: the first one covering Faraday's law and Lenz's law; the second, motional electromotive force and induced electric fields; and the last one dealing with Foucault's currents. The classes took place at UFES, São Mateus. During classes, students were receptive to the method we used and, by means of conceptual tests, we verified their learning was benefited.
\end{abstract}

Keywords: physics teaching, active learning, think-pair-share.

\section{Introdução}

Em sua teoria da aprendizagem significativa, David Ausubel propôs que o aprendizado significativo de novos conceitos eram derivados de conhecimentos préexistentes na estrutura cognitiva dos estudantes, denominados subsunçores ou conceitos-âncora. Esses conhecimentos não aleatórios, mas potencialmente evolutivos, servem como base para um novo conceito. Além dos subsunçores, dois preceitos são essenciais para que a aprendizagem seja significativa, são eles: o material potencialmente significativo e a disposição do aprendiz em aprender [1-2].

$\mathrm{Na}$ aprendizagem ativa, o objetivo principal é a participação ativa do estudante em sala de aula como mediador do conhecimento. Tal tipo de aprendizado se baseia no uso de métodos e estratégias para garantir essa participação e valorizar o trabalho em conjunto, sendo comum o uso de mídias e experimentos para estes fins [3]. Vários métodos já vem sendo aplicados no Brasil, tais como Ensino sob medida (Just in Time Teaching), Instrução por pares (Peer Instruction), a 
combinação destes [4], SCALE UP [5] e sala de aula invertida (Flipped Classroom) [6]. Diversas instituições de ensino superior aplicam esses métodos tanto como forma de pesquisa em ensino quanto para buscar uma melhor formação de seus estudantes.

Em nosso trabalho, utilizamos a aprendizagem significativa juntamente com a aprendizagem ativa para preparar uma sequência de três aulas sobre o tema de indução eletromagnética em uma turma de engenharia na Universidade Federal do Espirito Santo, campus São Mateus. Utilizamos como subsunçores os conceitos de fluxo magnético e corrente elétrica para preparar um material exclusivo com o auxílio de experimentos, um vídeo e do PowerPoint. Tal material contou com experimentos de lei de Faraday e lei de Lenz, um vídeo mostrando um experimento de correntes de Foucault, além de conjuntos de slides contendo séries de questões simples sobre os subsunçores e também com conclusões sobre o conteúdo. O material foi feito dessa forma para que os estudantes construíssem os novos conceitos respondendo tais questões. Ao final de cada aula executamos 0 método ativo chamado PensarEmparelhar-Compartilhar (Think-Pair-Share) [7], que tem como objetivo ampliar os conhecimento dos estudantes ao incentivar o estudo em grupo e a troca de conhecimento. Ao fim da terceira aula, além da aplicação do método, aplicamos um teste geral com o conteúdo das três aulas cujo objetivo foi analisar a retenção de conteúdo.

A seguir, descrevemos em maiores detalhes o método, a metodologia utilizada e os resultados obtidos.

\section{Metodologia}

Iniciamos a sequência de aulas com um experimento qualitativo de lei de Faraday (Figura 1) e um de lei de Lenz (Figura 2).

Esses experimentos tiveram como objetivo captar a atenção dos alunos já num primeiro momento. Nesse sentido, acreditamos termos sido bem sucedidos, pois os estudantes aparentaram interesse nos experimentos e em suas respectivas explicações.

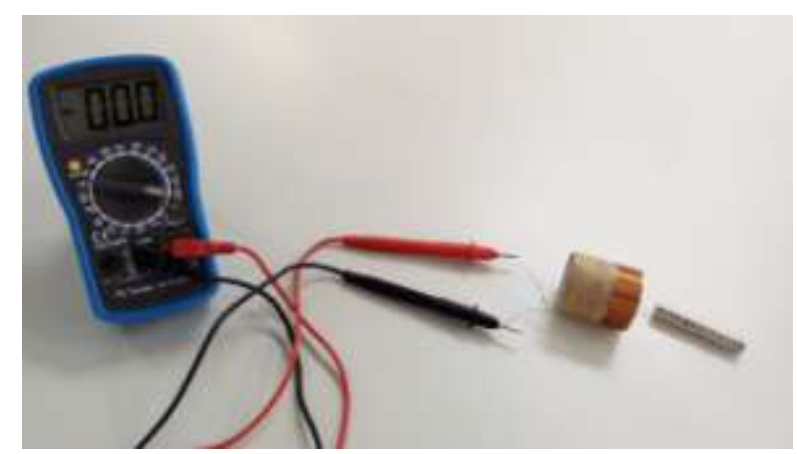

Figura 1. Experimento de lei de Faraday para a primeira aula.

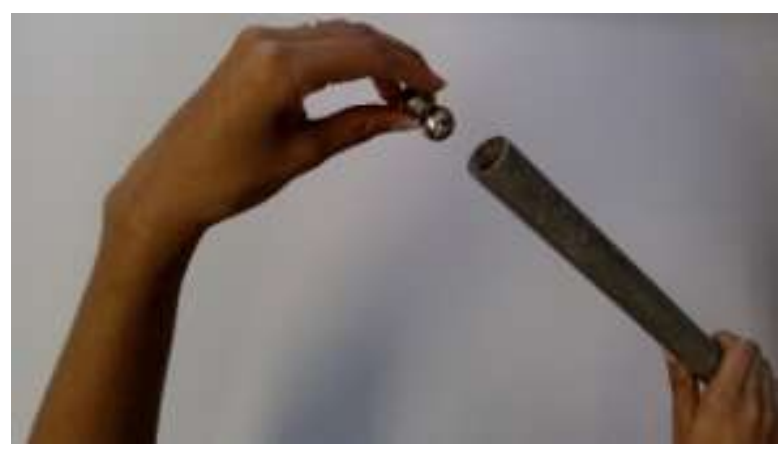

Figura 2. Experimento de lei de Lenz para a primeira aula.

Para guiar as aulas, utilizamos slides de PowerPoint previamente preparados. Com estes, sequências de perguntas foram feitas pelo professor e respondidas de maneira espontânea pelos alunos, sendo utilizadas para construir os conceitos de indução eletromagnética, campo elétrico induzido e correntes de Foucault. Nas Figuras 3 e 4, ilustramos um exemplo de slide com questão e outro com sua respectiva resposta.

Como podemos representar o campo magnético de um imã?

Figura 3. Exemplo de slide com questão utilizado em aula. 


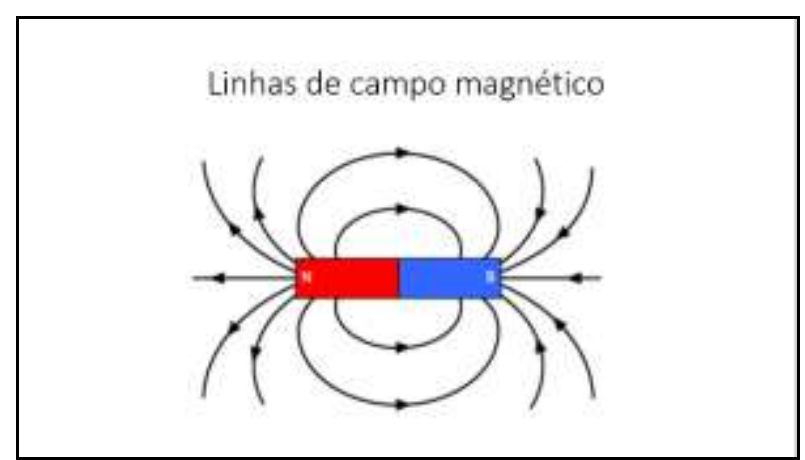

Figura 4. Exemplo de slide com resposta utilizado em aula.

Ao final de cada aula, aplicamos o método ativo Pensar-Emparelhar-Compartilhar. Este consiste em apresentar uma questão para os estudantes e deixar que pensem sobre ela, individualmente, por um tempo, podendo fazer anotações sobre tal questão, chegando ou não há uma conclusão. Logo após isso, os estudantes se agrupam e discutem sobre a questão, posteriormente compartilhando suas conclusões entre seus colegas de grupo ou para toda a turma. Porém, adaptamos esse método para que pudéssemos quantificar as respostas. Essa adaptação fez o método ser aplicado segundo os seguintes passos:

1 - Apresentamos um teste conceitual de múltipla escolha para os estudantes.

2 - Demos a eles 1 minuto para que pudessem responder individualmente.

3 - Passado esse tempo, juntamos estes em pequenos grupos.

4 - Demos mais 2 minutos para que discutissem e respondessem novamente a questão.

5 - Apresentamos a resposta e a explicamos.

Ao fim, abrimos espaço para esclarecimento de qualquer dúvida que tenha restado. Não surgindo questionamentos extras, seguimos adiante para a próxima pergunta.

Ao todo, apresentamos cinco testes conceituais ao fim de cada aula, versando sobre o tema da mesma. A Figura 4 mostra exemplos de testes conceituais que apresentamos aos alunos.

Ao final da última aula, aplicamos um teste geral, também de múltipla escolha, que englobou todo o assunto lecionado nas três aulas onde foi aplicado o método.
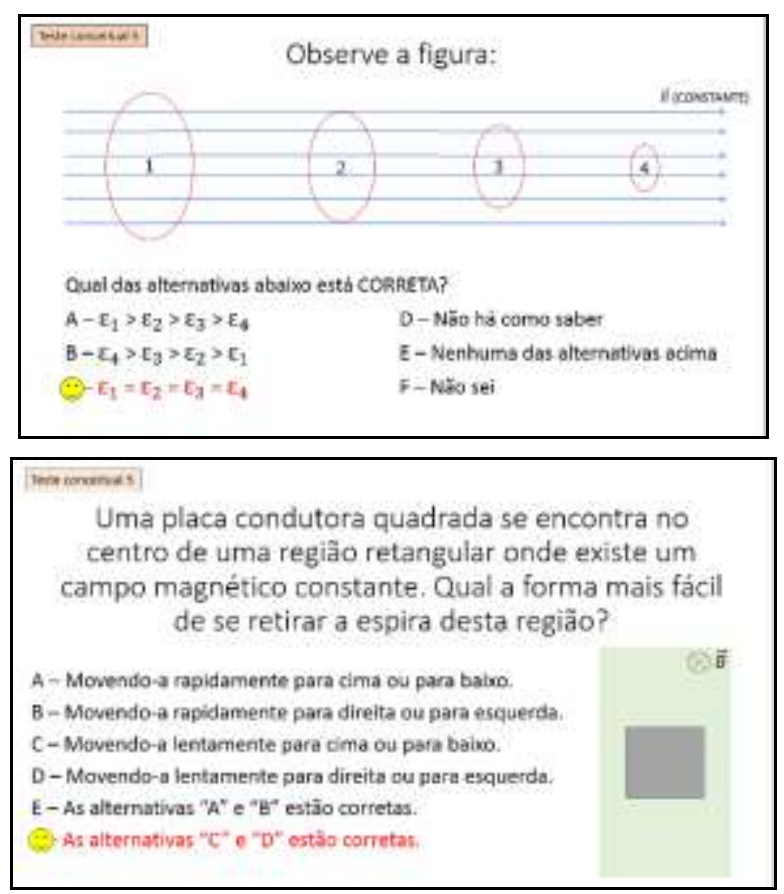

Figura 4. Exemplos de testes conceituais utilizados nas aulas.

\section{Resultados}

A coleta de dados foi feita com a contagem das respostas dadas pelos alunos individualmente e pelas respostas dadas por eles depois da discussão em grupos. Ao todo, foram 15 testes conceituais e um teste final com 9 questões englobando o conteúdo das três aulas.

Na primeira aula o tema dos testes foi lei de Faraday e lei de Lenz, e contou com a presença de 38 alunos. Na segunda aula, onde compareceram 54 alunos, os testes versaram sobre força eletromotriz produzida pelo movimento e campo elétrico induzido. Por fim, na terceira aula, o tema foi correntes de Foucault e compareceram 50 alunos. O Quadro 1 mostra o número de acertos que os estudantes tiveram antes e depois da discussão em grupo em cada aula. Notemos que o quarto teste conceitual da segunda aula foi anulado, pois posterior à sua aplicação notamos que haviam duas alternativas corretas.

Ao final da terceira aula, aplicamos um teste final com 9 questões conceituais, de múltipla escolha, contendo todo o conteúdo das três aulas. Os alunos tiveram 40 minutos para responder as questões. O Quadro 2 mostra o número de alunos por quantidade de acertos nesse teste final.

\begin{tabular}{|l|c|c|c|c|c|}
\hline Aula 1 & $\mathrm{T} 1$ & $\mathrm{~T} 2$ & $\mathrm{~T} 3$ & $\mathrm{~T} 4$ & $\mathrm{~T} 5$ \\
\hline
\end{tabular}




\begin{tabular}{|c|c|c|c|c|c|}
\hline Antes & 17 & 28 & 19 & 37 & 8 \\
\hline Depois & 31 & 33 & 30 & 37 & 14 \\
\hline Aula 2 & $\mathrm{T} 1$ & $\mathrm{~T} 2$ & $\mathrm{~T} 3$ & $\mathrm{~T} 4$ & $\mathrm{~T} 5$ \\
\hline Antes & 39 & 22 & 14 & - & 37 \\
\hline Depois & 50 & 30 & 27 & - & 47 \\
\hline Aula 3 & $\mathrm{T} 1$ & $\mathrm{~T} 2$ & $\mathrm{~T} 3$ & $\mathrm{~T} 4$ & $\mathrm{~T} 5$ \\
\hline Antes & 26 & 26 & 9 & 14 & 29 \\
\hline Depois & 38 & 32 & 29 & 31 & 43 \\
\hline
\end{tabular}

Quadro 1. Número de acertos nos testes conceituais antes e depois das discussões em grupos em cada aula.

\begin{tabular}{|l|l|l|l|l|l|l|l|l|}
\hline № acertos & 1 & 2 & 3 & 4 & 5 & 6 & 7 & 8 \\
\hline № alunos & 2 & 4 & 7 & 12 & 11 & 7 & 6 & 1 \\
\hline
\end{tabular}

Quadro 2. Número de acertos dos alunos no teste final.

\section{Conclusão}

No geral, tivemos a impressão que os estudantes se mostraram receptivos à metodologia. Foram muito respeitosos e curiosos, fazendo perguntas sobre a matéria e sobre o próprio método de ensino. $\mathrm{O}$ uso de experimentos no início da primeira aula teve um efeito positivo aos instigar a curiosidade dos estudantes, captando suas atenções para o resto da aula. Quanto ao método Pensar-EmparelharCompartilhar, este se mostrou bem aceito. Os estudantes discutiam os testes conceituais, defendiam suas respostas e se mostravam bastante satisfeitos quando confirmavam o acerto. A impressão geral é que eles ficavam entusiasmados ao aplicar imediatamente nos testes conceituais o que estavam aprendendo.

Dos resultados apresentados na seção anterior, comparando as respostas dos estudantes antes e depois das discussões em grupo, observamos um aumento nos acertos dos testes conceituais. Apesar de ser necessário aplicarmos este método em outras turmas e para mais estudante para atestarmos sobre a eficiência do método, este resultado nos dá boas perspectivas.
Com o desempenho apenas mediano observado no teste final, percebemos que os estudantes se satisfizeram apenas em assistir as aulas diferentes das tradicionais, mas não reforçaram o aprendizado em casa. Isso nos sugere que a eficácia do método que utilizamos deve depender também do empenho dos estudantes fora da sala de aula, assim como ocorre com os métodos tradicionais de ensino.

Temos como perspectiva continuar aplicando esse método no tema indução eletromagnética em outras turmas cursando a disciplina de eletromagnetismo e também em outros conteúdos de física. Com isso, esperamos testar melhor não só a eficiência do método mas também sua versatilidade com diferentes assuntos.

\section{Referências}

[1] Moreira, M. A. Aprendizagem Significativa: a teoria e textos complementares. São Paulo. Livraria da Física, 2011.

[2] O que é afinal aprendizagem significativa?, Porto Alegre. Disponível em <https://www.if.ufrgs.br/ moreira/ oqueeafinal.pdf>. Acesso em 12 julho de 2017.

[3] Berbel, N. A. N. As metodologias ativas e a promoção da autonomia de estudantes. Semina: Ciências Sociais e Humanas, v. 32, n. 1, p. 25, 2011.

[4] Araújo, I. S.; Mazur, E. Instrução pelos colegas e ensino sob medida: uma proposta para o engajamento dos alunos no processo de ensino-aprendizagem de física. Caderno Brasileiro de Ensino de Física, v. 30, n.2, p. 362, 2013

[5] IFUSP adota método de ensino que aumenta a participação do aluno em sala de aula, São Paulo. Disponível em <http://portal.if.usp.br/imprensa/pt-br/ node/665>. Acesso em 9 maio de 2017.[6] Trevelin, A. T. C.; Pereira, M. A. A. A utilização da "sala de aula invertida" em cursos superiores de tecnologia: comparação entre o modelo tradicional e o modelo invertido "flipped classroom" adaptado aos estilos de aprendizagem. Revista de Estilos de Aprendizagem, v. 6, n. 12, 2013.

[7] Sampsel, Ariana, Finding the Effects of Think-PairShare on Student Confidence and Participation. Honors Projects. Paper 28. 2013. 